Supplementary Information

\title{
Fe Enhanced Visible-Light-Driven Nitrogen Fixation on BiOBr Nanosheets
}

Yang $\mathrm{Liu}^{\dagger}$, Zhuofeng $\mathrm{Hu}^{*, \neq}$, and Jimmy C. Yu*,†

tDepartment of Chemistry, The Chinese University of Hong Kong, Shatin, New

Territories, Hong Kong, China. 999077

Email:E-mail:jimyu@cuhk.edu.hk

School of Environmental Science and Engineering, Guangdong Provincial Key

Laboratory of Environmental Pollution Control and Remediation Technology, Sun

Yat-sen University, Guangzhou 510275, China

Email:huzhf8@mail.sysu.edu.cn 
a

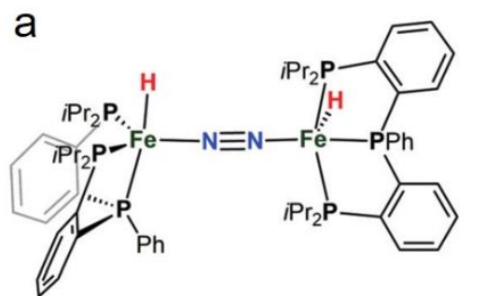

b

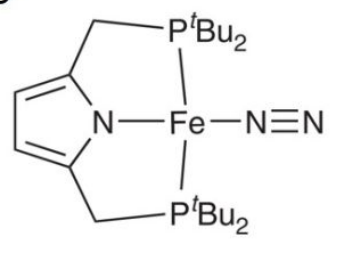

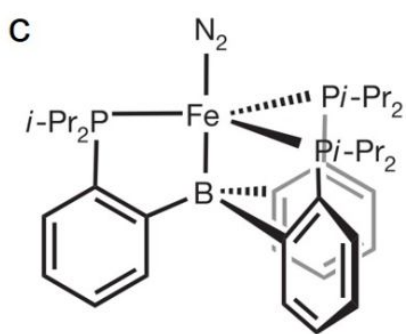

Figure S1. Previously reported Fe-contained organometallic photocatalysts. (a) $\left[\mathrm{P}_{2}{ }^{\mathrm{P} P h} \mathrm{Fe}(\mathrm{H})\right]_{2}\left(\mu-\mathrm{N}_{2}\right)$. Reproduced with permission. ${ }^{1}$ Copyright 2017 , Wiley-VCH. (b) $\left[\mathrm{Fe}\left(\mathrm{N}_{2}\right)(\mathrm{PNP})\right]$. Reproduced with permission. ${ }^{2}$ Copyright 2016, Nature Publishing Group. (c) (TPB)Fe(N2). Reproduced with permission. ${ }^{3}$ Copyright 2013, Nature Publishing Group.

a

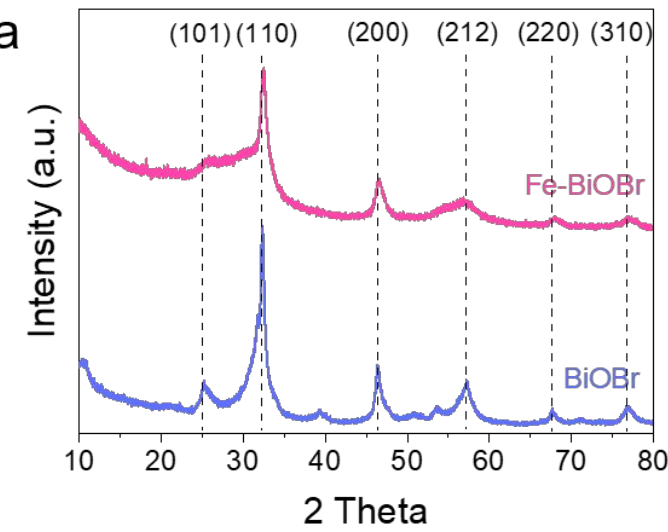

C

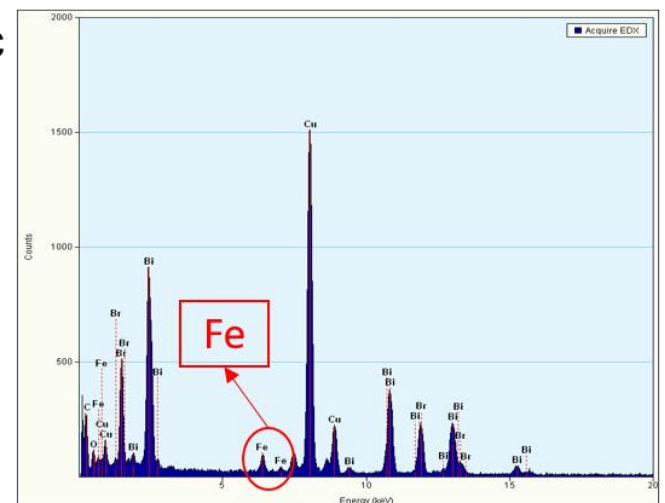

$b$

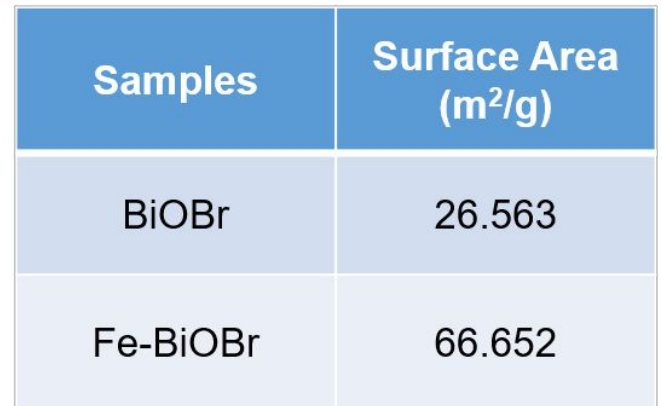

d

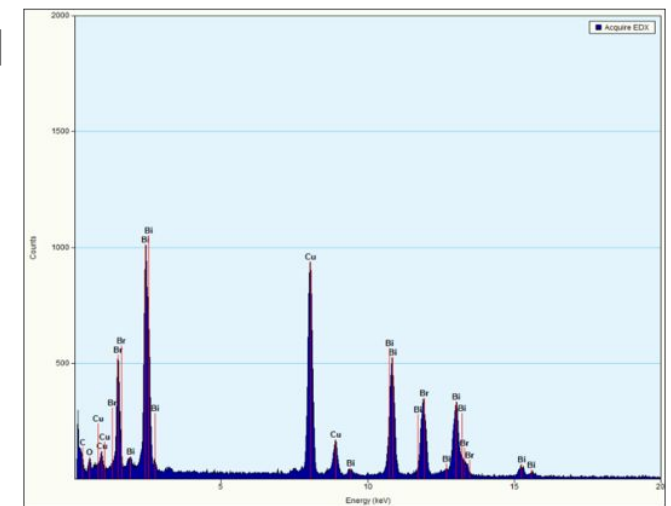

Figure S2. The XRD patterns (a) and BET surface area (b) of $\mathrm{Fe}-\mathrm{BiOBr}$ and $\mathrm{BiOBr}$. The EDX spectra of $\mathrm{Fe}-\mathrm{BiOBr}(\mathrm{c})$ and $\mathrm{BiOBr}(\mathrm{d})$. The peaks circled are aligned to $\mathrm{Fe}$. 

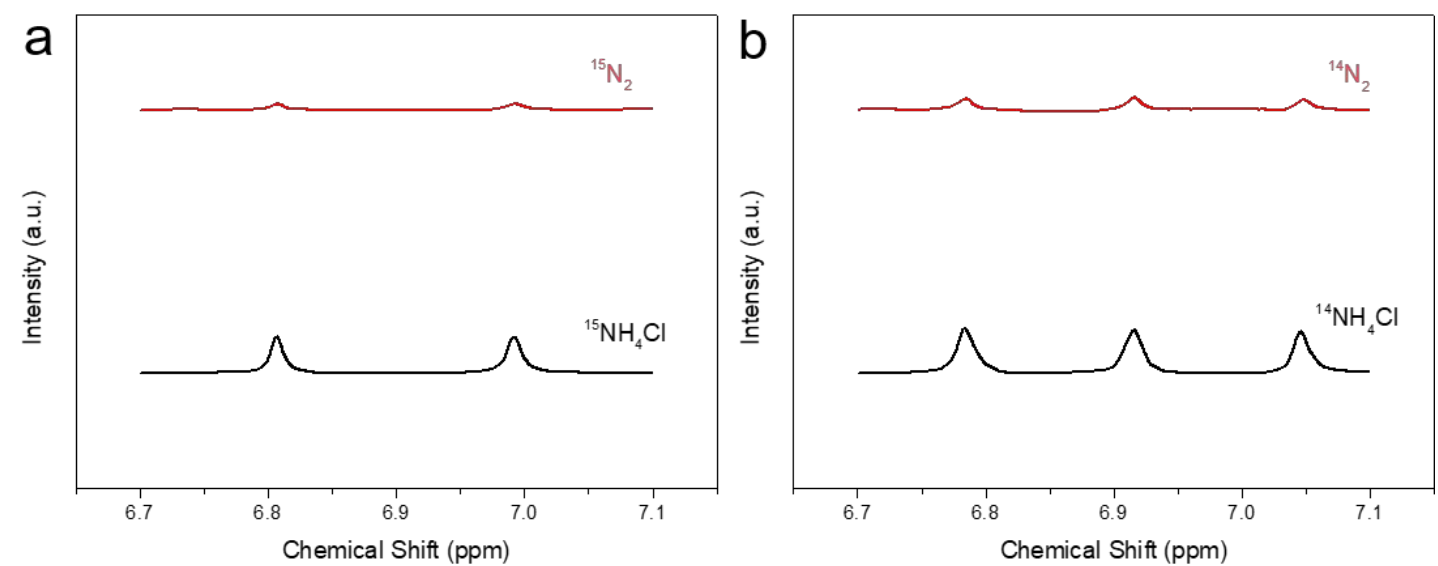

Figure S3. The 1H-NMR spectra of the sample solution bubbling with ${ }^{15} \mathrm{~N}_{2}$ (a) and ${ }^{14} \mathrm{~N}_{2}$ (b) after $\mathrm{N} 2$ photofixation for an hour. The isotope labelled $\mathrm{NH}_{4} \mathrm{Cl}$ are shown as references.
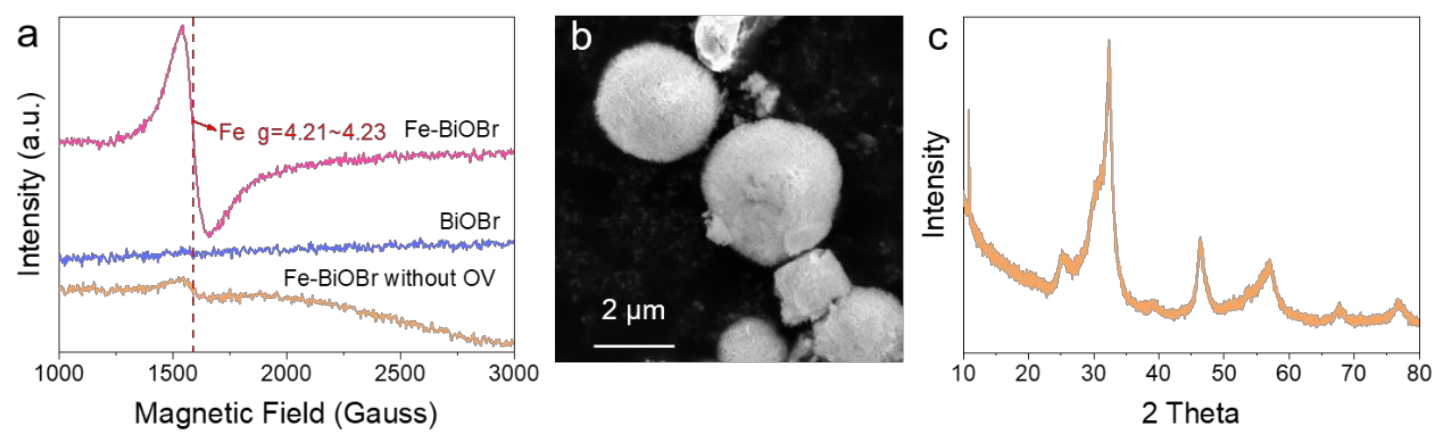

Figure S4. (a) The EPR spectra of $\mathrm{Fe}-\mathrm{BiOBr}, \mathrm{BiOBr}$, and $\mathrm{Fe}-\mathrm{BiOBr}$ without $\mathrm{OV}$. The Fe signal at 1600-1700 Gauss is assigned to $g$ value of 4.21-4.23. (Some unidentified fast relaxing $\mathrm{Fe}$ (III) species might be generated after calcination, resulting in a broad signal in the background. Thus the signal seemed to decrease.) The SEM image (b) and the XRD pattern (c) of the Fe-BiOBr without OV. 

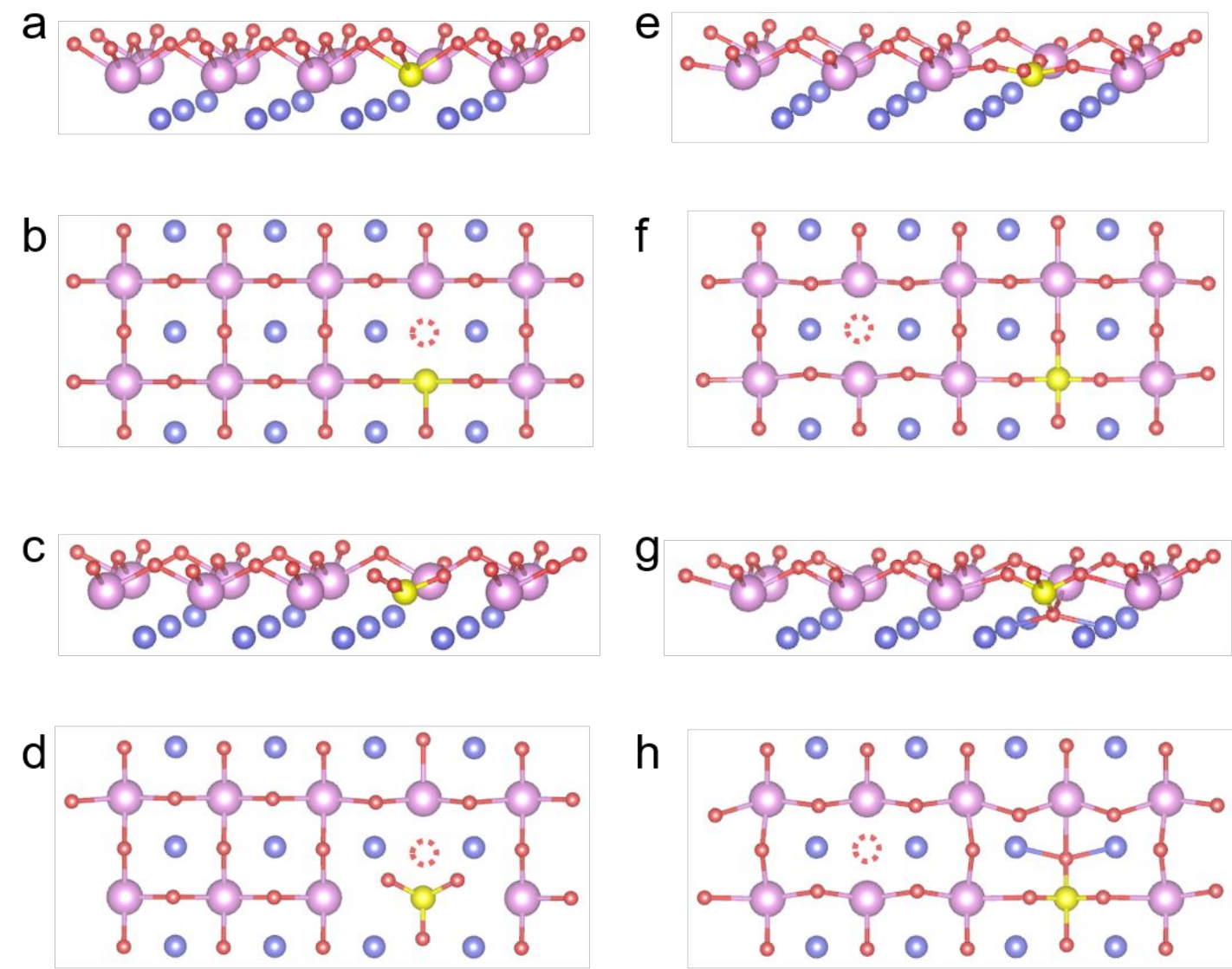

$\mathrm{Bi}$

$\mathrm{Fe} O \mathrm{Br} \circ \mathrm{O} \quad \mathrm{OV}$

Figure S5. The crystal structure of $\mathrm{Fe}-\mathrm{BiOBr}$ with an $\mathrm{OV}$ near $\mathrm{Fe}$ (a-d) and away from $\mathrm{Fe}$ (e-h). (a), (b), (e) and (f) are unoptimized structures, while (c), (d), (g) and (h) are optimized. (a), (c), (e) and (g) are 3D view. (b), (f), (d), and (h) are top view.

The formation energy of an $\mathrm{OV}$ is calculated by the equation $\mathrm{S} 1$ :

$$
\mathrm{E}_{\mathrm{f}}=\mathrm{E}_{\text {with-Ov- }} \mathrm{E}_{\text {without-OV }}
$$

Where $\mathrm{E}_{\mathrm{f}}$ is the formation energy of OV, $\mathrm{E}_{\text {with-Ov }}$ the energy of the system with an $\mathrm{OV}$, and $\mathrm{E}_{\mathrm{without}-\mathrm{OV}}$ the energy of the system without OV. Two structures were established in which the $\mathrm{OV}$ is near (Figure $\mathrm{S} 5 \mathrm{a}-\mathrm{c}$ ) and far away from (Supplementary Figs 5d-f) the Fe, respectively.

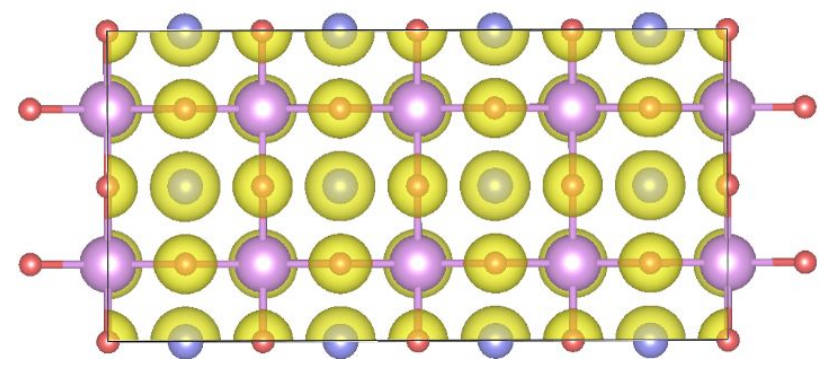

Figure S6. . Charge density map of pure $\mathrm{BiOBr}$ (top view). 


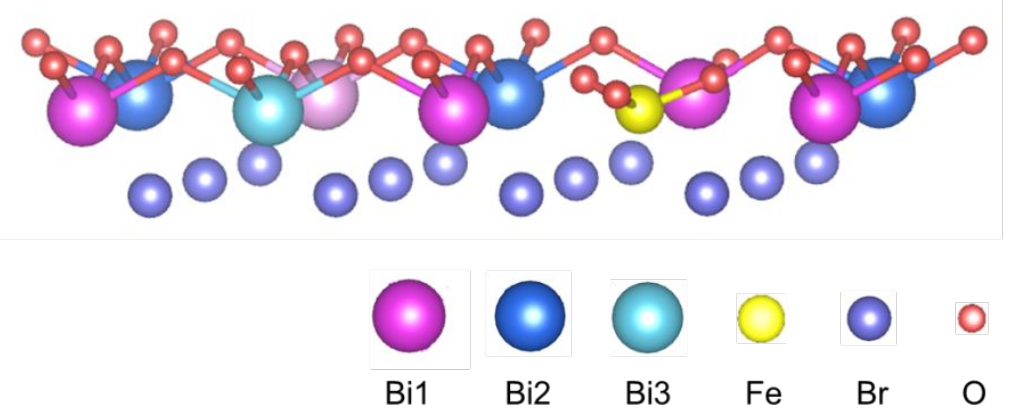

Figure S7. Different $\mathrm{Bi}$ atoms around $\mathrm{Fe}$ in $\mathrm{Fe}-\mathrm{BiOBr}$

Table S1. Number of valence electrons on $\mathrm{Bi}$ around $\mathrm{Fe}$ in $\mathrm{Fe}-\mathrm{BiOBr}$.

Elements Distance from $\mathrm{Fe}$ Isolate state State in $\mathrm{Fe}-\mathrm{BiOBr}$

$(\AA)$

\begin{tabular}{llll}
\hline Bi1 & 3.923 & 5.000 & 1.673 \\
Bi2 & 5.548 & 5.000 & 1.907 \\
Bi3 & 7.846 & 5.000 & 2.054 \\
\hline
\end{tabular}
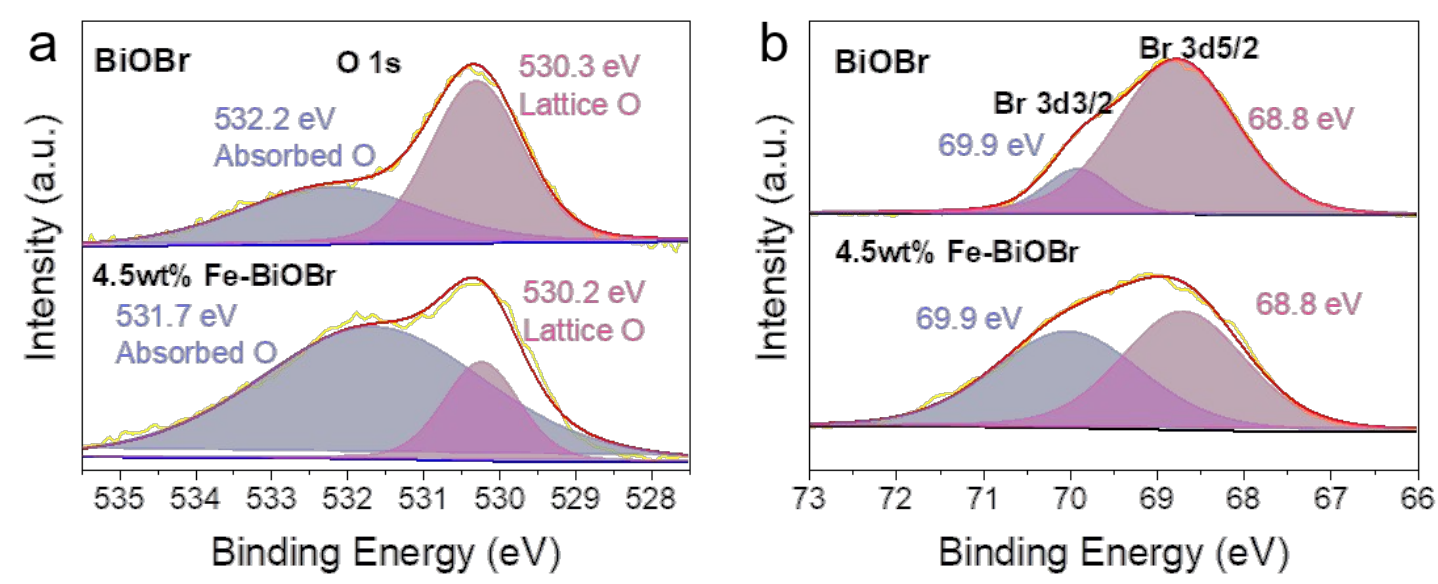

Figure S8. XPS spectra of O 1s (a) and $\mathrm{Br} 3 \mathrm{~d}(\mathrm{~b})$.

In Figure S8a, the XPS spectra of O 1s can be resolved into two peaks at $532.2 \mathrm{eV}$ and $530.3 \mathrm{eV}$, attributed to the $\mathrm{O}$ in the surface components and lattice $\mathrm{O}$ in $\mathrm{BiOBr}$, respectively. ${ }^{4}$ These two peaks both shift to the lower binding energy after the incorporation of the Fe. Figure $\mathrm{S} 8 \mathrm{~b}$ displays the $\mathrm{Br} 3 \mathrm{~d} 3 / 2$ and $3 \mathrm{~d} 5 / 2$ characteristic peaks at around $69.9 \mathrm{eV}$ and $68.8 \mathrm{eV}$, respectively. 


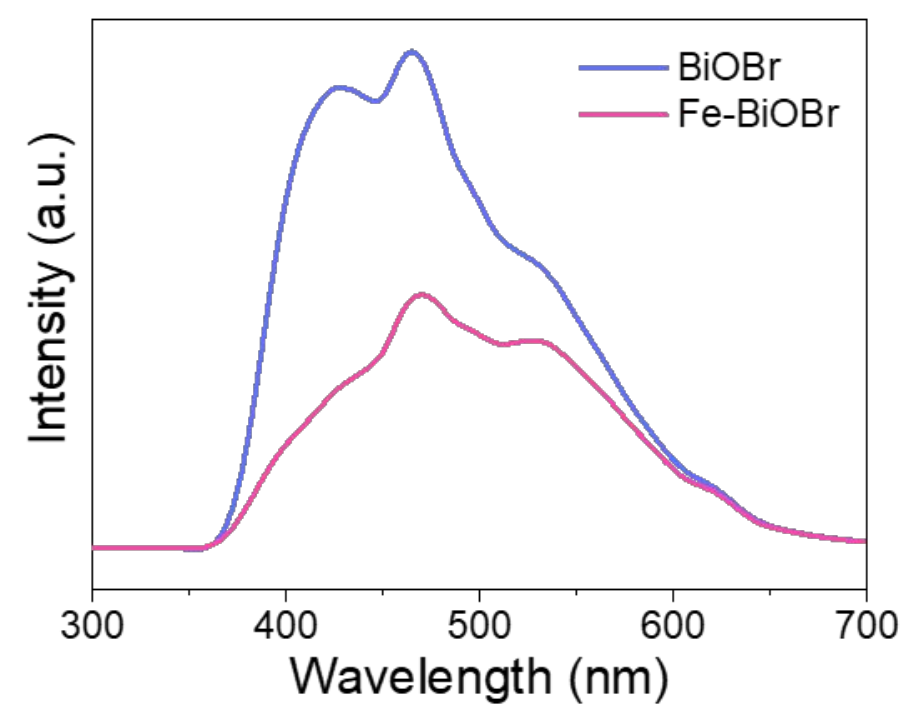

Figure S9. PL spectra of $\mathrm{BiOBr}$ and $\mathrm{Fe}-\mathrm{BiOBr}$.

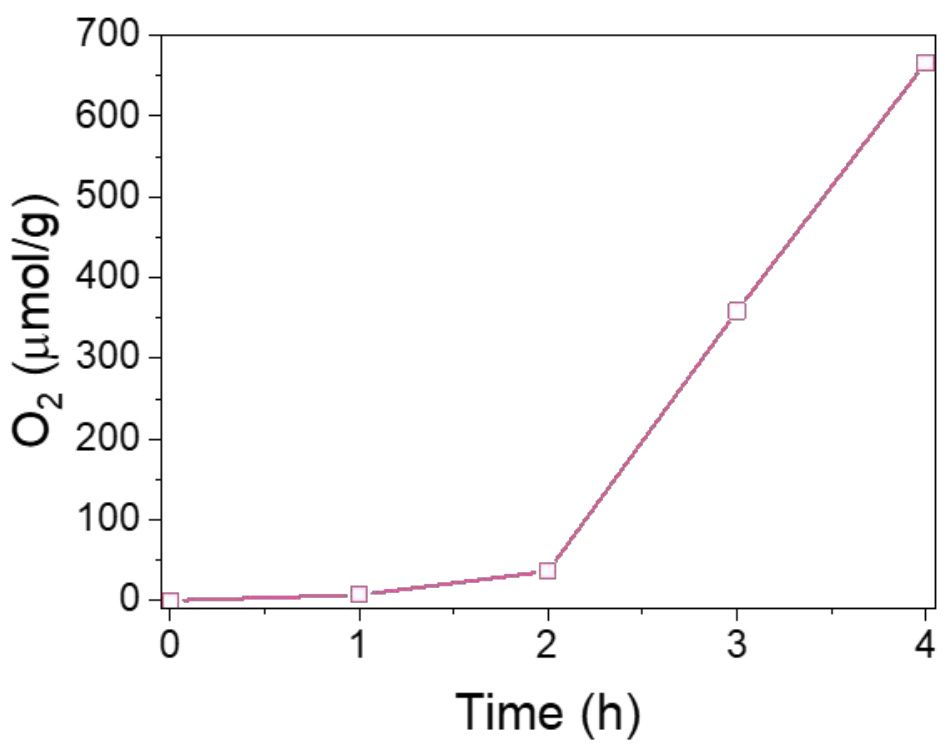

Figure S10. $\mathrm{O}_{2}$ evolution during $\mathrm{N}_{2}$ photofixation.

Table S2. The amount of Fe in the series of Fe-BiOBr samples detected by ICP.

\begin{tabular}{cc}
\hline $\begin{array}{c}\mathrm{Fe} / \mathrm{Bi} \text { in the precursor } \\
\text { (molar ratio) }\end{array}$ & $\mathrm{wt} \% \mathrm{Fe}$ in the catalyst \\
\hline 0.1 & 1.7 \\
0.2 & 3.5 \\
0.3 & 4.5 \\
0.5 & 8.3 \\
1 & 14.5 \\
\hline
\end{tabular}

\section{References}

(1) Buscagan, T. M.; Oyala, P. H.; Peters, J. C., N-2-to-NH3 Conversion by a 
triphos-Iron Catalyst and Enhanced Turnover under Photolysis Angew. Chem., Int. Ed. 2017, 56 (24), 6921-6926.

(2) Kuriyama, S.; Arashiba, K.; Nakajima, K.; Matsuo, Y.; Tanaka, H.; Ishii, K.; Yoshizawa, K.; Nishibayashi, Y., Catalytic transformation of dinitrogen into ammonia and hydrazine by iron-dinitrogen complexes bearing pincer ligand Nat. Commun. 2016, 7, 12181.

(3) Anderson, J. S.; Rittle, J.; Peters, J. C., Catalytic conversion of nitrogen to ammonia by an iron model complex Nature 2013, 501 (7465), 84.

(4) Wang, S. Y.; Hai, X.; Ding, X.; Chang, K.; Xiang, Y. G.; Meng, X. G.; Yang, Z. X.; Chen, H.; Ye, J. H., Light-Switchable Oxygen Vacancies in Ultrafine Bi5O7Br Nanotubes for Boosting Solar-Driven Nitrogen Fixation in Pure Water Adv. Mater. 2017, 29 (31), 7. 